\title{
A CASE REPORT OF NASOPHARNGEAL CARCINOMA IN CHILDREN PRESENTED WITH RT. NECK MASS
}

\author{
AKM AMIRUL MORSHED ${ }^{1}$, SHAHNOOR ISLAM ${ }^{2}$, ZAKIA RAHMAN $^{3}$, HELENA BEGUM $^{4}$, SYED AHSAN ALI ${ }^{5}$
}

\begin{abstract}
Nasopharyngeal carcinoma is a rare disease in children. It present with mass in the nasopharynx or neck swelling. Recently a six year old boy was diagnosed as a case of NPC and treated with standard chemotherapy. The boy was presented with neck swelling, palatal palsy and ear discharge. The patient was diagnosed by lymph node biopsy and immunohistochemistry. The diagnosis was delayed for 4 months which usually occur in our country. He was diagnosed by lymph node biopsy and immunohistochemistry. He was treated with standard protocol based chemotherapy.
\end{abstract}

Key words : Nasopharyngeal carcinoma , children, chemotherapy.

\section{Introduction}

Nasopharyngeal carcinoma (NPC) is a tumor arising from the epithelial lining of the nasopharynx. It is not an uncommon tumour of head and neck region in adults. The occurance of the tumour in childhood is very rare ${ }^{1}$. It had been estimated that $5 \%$ of primary malignant tumours in children originate in the area of head and neck $^{2}$, while nasopharyngeal carcinoma

1. Dr. AKM Amirul Morshed, Associate Professor, Paediatric Haematology and Oncology, Dhaka Medical College Hospital, Dhaka

2. Dr. Shahnoor Islam, Assistant Professor, Paediatric Surgery, Dhaka Medical College Hospital, Dhaka

3. Dr. Zakia Rahman, Honorary Medical Officer, Paediatric Haematology and Oncology, Dhaka Medical College Hospital, Dhaka

4. Dr. Helena Begum, Assistant Professor, Paediatric Haematology and Oncology, Bangabandhu Sheikh Mujib Medical University, Dhaka

5. Dr. Syed Ahsan Ali, Associate Professor, Surgery, Uttara Women Medical College Hospital , Dhaka

Correspondence to : Dr. AKM Amirul Morshed, Associate Professor, Paediatric Haematology and Oncology, Dhaka Medical College Hospital, Dhaka. E-mail: amirul_morshed63@yahoo.com constitutes $2 \%$ of head and neck malignant tumours in children ${ }^{3}$. The World Health Organization (WHO) recognizes three different histologic subtypes of NPC(1) Squamous cell carcinoma(2)Non-keratinizing carcinoma(3) Undifferentiated carcinoma ${ }^{4}$.

Naso-pharyngeal carcinoma in children is a relatively rare neoplasm in Caucasian population and an uncommon malignancy in India and Bangladesh. It is estimated to contribute about $0.25 \%$ of all cancers in North Americans, whereas in Chinese it is a common malignancy and accounts for $18 \%$ of all malignant neoplasms in adult ${ }^{5}$. Exact incidence in population of Bangladesh is not known. The highest incidence of this disease occurs in Guangdong Province of Southern China, where the risk may be as high as $30-50 / 100,000$ persons/year 6 . In Indonesia, the incidence is approximately $4.7 / 100,000$ persons/ year ${ }^{3}$ Aetiological factors have been linked to genetic, environmental, dietary factors (nitrosoamines) and the Epstein Barr virus ${ }^{7}$.

Usual manifestations of NPC include neck lump due to metastasis to cervical lymph nodes. Ear fullness, hearing loss due to blockage of eustachian tubes along with nasal bleeding and obstruction ${ }^{8}$. Ophthalmoneurological manifestations due to cranial nerve paralysis and cutaneous involvement are very rare. Treatment of NPC depends on how far the cancer has spread. For stages 0 , I and II, standard treatment is radiation therapy aimed at the nasopharyngeal tumor and nearby lymph nodes of the neck.

Here we are going to present a child suffering from nasopharyngeal carcinoma which is extremely rare case in context of Bangladesh. 


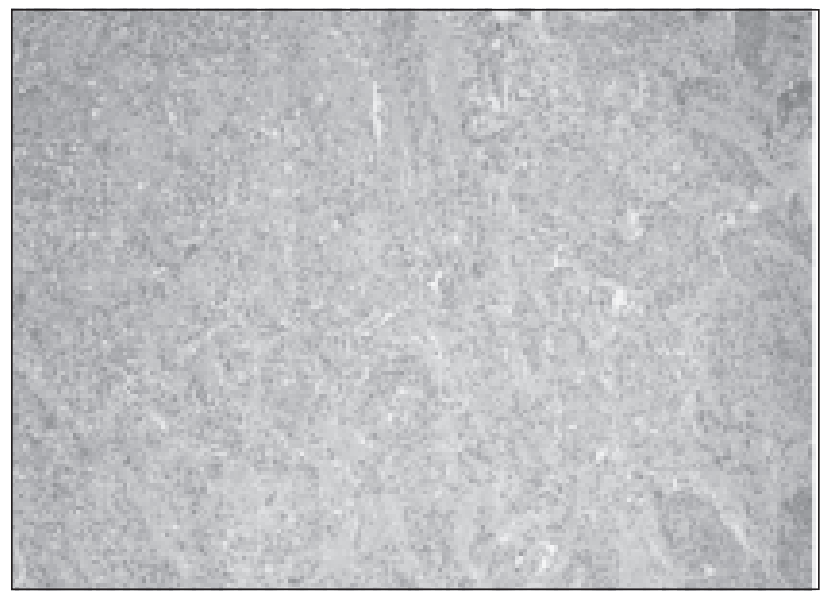

A

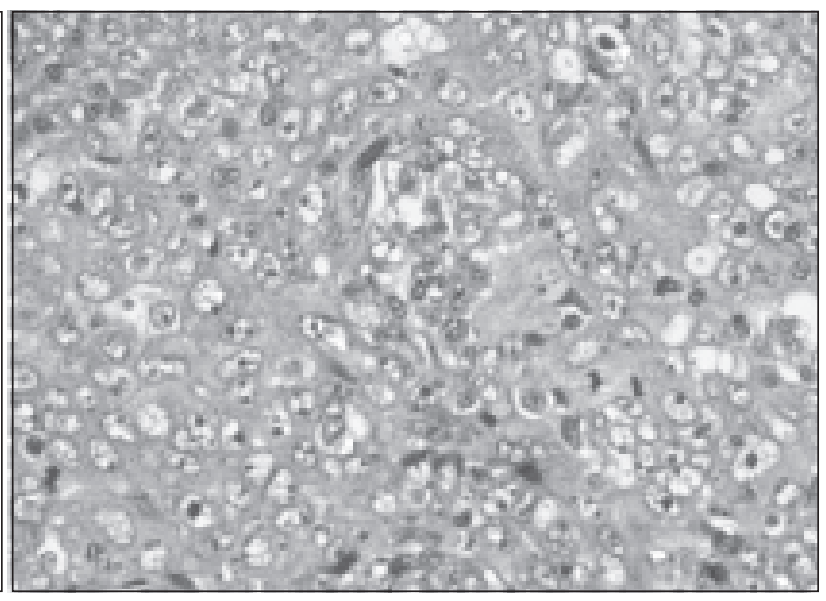

B

Fig.-1 (A \& B): Histopathological view of the patient (Nasopharyngeal carcinoma)

\section{Case Report}

A 6-yr old boy presented with rt sided neck swelling for 4 months. He had $\mathrm{H} / \mathrm{O}$ low grade fever and nasal regurgitation with difficulty in deglutition and swallowing for same duration. He had restricted neck movement in rt side. There was no $\mathrm{H} / \mathrm{O}$ sore throat, epistaxis, snoring, change in voice (rhinolalia clausa) or otitis media. There was no H/O TB contact also. On examination patient was irritable and vitals were stable. The largest cervical lymph node was measured about $(7 \mathrm{~cm} \times 3 \mathrm{~cm})$ was palpable on rt side of neck. It was hard in consistency and fixed with underlying structure but overlying skin was free. Examination of chest, CVS and abdomen were normal.

CNS: Mental functions were normal but nasal regurgitation and difficulty in swallowing of both solid and liquid were present due to soft palate paresis. There was weakness in rt. sternocleidomastoid muscle. All cranial nerve functions were intact but XI nerve. Examination of upper and lower limb was normal. There was no sign of cerebellar dysfunction or meningeal irritation. Skull,orbit and spine were normal.

On investigation, $X$-Ray reveals a soft tissue swelling on posterior wall of nasopharynx without any bony erosion. Posterior rhinoscopy could not be done. Fine needle aspiration of swelling reveals secondary deposits in neck. Biopsy was taken from enlarged lymph node and was reported as metastatic nasopharyngeal carcinoma.

The patient was diagnosed as nasopharyngel carcinoma with involvement of cranial nerve XI on the rt side with metastasis to ipsilateral cervical lymph node. He was treated with combination chemotherapy with 5-Flourouracil and cisplatin. The patient was given 5 cycle of chemotherapy and is on follow up.

\section{Discussion}

Nasoparyngeal carcinoma in children is a rare and does not attract medical attention before it spreads to regional lymph nodes or at a later stage ${ }^{9}$. Hodgkins and other malignant lymphomas and soft tissue sarcomas were more common. Tumour registry in Manchester, U. K., listed 12 cases of carcinoma in nasopharynx in children up to 15 years of age, out of a total of 1482 cases of malignant diseases of childhood from 1954-1980 ${ }^{10}$. Fernandez identified 10 patients under 15 years of age with a diagnosis of carcinoma nasopharynx in their study spanning 17 years ${ }^{10 .}$ Carcinoma of the nasopharynx in adults is endemic in Chinese and other South-East Asians, where the age incidence rate begins to rise at the end of 2 nd decade of life, reaches a peak in the fourth decade and then stays at a plateau ${ }^{11}$. There is also a high proportion of NPC in patients below 20 years. Nasopharyngeal carcinoma in children presents mainly with cervical lymphadenopathy ${ }^{1,3}$. This common (60-90\%) presentation of nasopharyngeal carcinoma has been related to the rich network of lymphatics in the nasopharynx ${ }^{1,10,12}$. Enlargement and extension of the tumor in the nasopharynx may result in symptoms of nasal obstruction, changes in hearing usually associated with blockage of the eustachian tube, direct extension into the ear and cranial nerve palsies. In our patient there was lymphadenopathy and ear problem. In children due to frequent upper 
respiratory tract infections, this rare tumour can, therefore, be masked, resulting in considerable delay in establishing the correct diagnosis. Our reported case is an example in this context. This case of nasopharyngeal carcinoma has the clinical presentation and diagnosis of NPC was found after 4 months. The presence of lymph node enlargement is the reason for him to seek medical attention. It has been observed that nasopharyngeal carcinoma that occurs in children and young adults is not a differentiated squamous carcinoma as keratinization in them is absent ${ }^{12}$. This tumour in this age group occurs more often as undifferentiated carcinoma or poorly differentiated epidermoid carcinoma ${ }^{3,12,13}$ The spread of nasopharyngeal tumors most commonly occurs via the blood and the lymphatics. NPC most commonly metastasizes to the cervical lymph nodes and presents as a unilateral neck lump in 50\%-70\% of patients ${ }^{14}$. It is the presentation of our case. Distant metastases are encountered in $5 \%-11 \%$ of the patients at the time of initial diagnosis ${ }^{15,16}$. This tumour may involve the cranial nerves in many ways. Firstly, the tumour may extend superiorly through foramen lacerum ${ }^{17}$, or cancer may break through the pharyngobasilar fascia and spread along vascular sheaths, thus extend within the skull base and lead to cranial nerve involvement ${ }^{18}$. Ophthalmic presentation as the initial presenting feature of nasopharyngeal carcinoma is uncommon. Patients may present with proptosis, diplopia, optic neuritis ${ }^{19}$. Orbital involvement from NPC is seen in $3.2 \%$ of cases ${ }^{19}$.Our case is free from orbital involvement. Lateral and posterior extension of the primary growth itself may involve the lower cranial nerves exiting from jugular and hypoglossal foramina. These lower cranial nerves may also be involved on their course while traversing the neck by the secondary deposits in the lymph nodes. In one study of North American patients, $20 \%$ had involvement of the cranial nerves at the time of diagnosis ${ }^{20}$. Rarely, a tumour may affect cranial nerve IX, X and XI and produce jugularforamen syndrome. In our case, he was suffered from XIth cranial nerve palsy.

Chemotherapy and radiation therapy are established mode of treatment for nasopharyngeal carcinoma in adults ${ }^{11}$. Same treatment when applied to children and young adults produces prompt and complete tumour regression jn almost all patients and results in cure in 30 to $50 \%^{1,12}$. The better 5 year survival rate of $50-62.5 \%$ in younger patients has documented despite the aggressive disease in them. Our patient was given only chemotherapy.

\section{References}

1. Fernandez $\mathrm{CH}$, Cangir A. Samaan NA et 01. Nasopharyngealcarcinoma in children. Cancer 1976; 37: 2787-2791

2. Healy G. Malignant tumours of the head and neck children: diagnosis and treatment. Am Otolaryngol Clin. $1980 ; 13: 483-488$

3. Cunningham MJ, Myers EN, Bluestone CD. Malignant tumours of the head and neck in children. A review. Int. J Paed Otolaryngol 1987; $13: 279-292.13$

4. Brennan B. Nasopharyngeal carcinoma. Orphanet JRare Dis 2006; 1:23

5. Neel HB III. Nasopharyngeal carcinoma: Clinical presentation, diagosis, treatment, and prognosis.Otorhinological Clinics of North America. 1985; 18(3): 479-90.

6. Fu KK. Treatment of tumors of the nasopharynx. In: Thawley SE, Panje WR, editors. Comprehensive management of head and neck tumors. Volume 1.WB Sunders. Philadelphia 1999.

7. Chang ET, Adami HO. The enigmatic epidemiology of nasopharyngeal carcinoma. Cancer Epidemiol Biomarkers Prev 2006; 15: 1765-77

8. Satar B, Tosun F and Ozkaptan Y. Nasopharyngeal carcinoma a report of two cases with unusual extension. T Klin J E.N.T 2001; 1: 45-50

9. Siddalingappa, SM Lingaswamy, SM Prashanth, KB Maheshwari, M and Indu C. Unusual presentation of nasopharyngeal carcinoma - a case report. Indian J Otolaryngol Head Neck Surg 2008; 60: 82-83.

10. Friedman I. In Systemic pathology 3rd Ed.Churchill Livingstone 1986 ; I : 142-I 43

11. Chew CT. In : Scou Browns' Otolaryngology, 5th ed.London, Butterworths 1987; 4 : 31 2-340.

12. Chan ATC, Teo PML, Johnson PJ. Nasopharyngeal carcinoma. Annals of Oncology 2002; 13: 1007-15

13. Jenkin RD, Anderson JR, Jerab B et al. Nasopharyngeal carcinoma - A retrospective thirty years of age. Cancer $1981 ; 47: 360-366$ 
14. Pathmanathan R. Pathology. In: Chong VFH, Tsao SY, editors. Nasopharyngeal Carcinoma. Hong Kong: Armour Publishing, 1997: 6-13

15. Teo PM, KwanWH, LeeWY, Leung SF, Johnson PJ. Prognosticators determining survival subsequent to distant metastasis from nasopharyngeal carcinoma. Cancer 1996; 77:2423-31.

16. Sham JS, Choy D. Prognostic factors of nasopharyngeal carcinoma: a review of 759 patients. Br J Radiol 1990; 63:51-8.

17. Ablashi DV, Levine PH, Pearson GR. Meeting report : Fourth International Symposium on Naso-pharyngeal Carcinoma Application of Field and Laboratory Studies to the Control of NPC. Cancer Res 1983; 43: 2375-8.

18. Schantz SP, Harrison LB, Hong WK. Head and Neck Cancer. In Cancer-Principles and Practice of Oncology. Devita VT, Hellman S, Rosenberg SA, (Eds.) 4th Edition, JB Lippincott Company, Philadelphia, 1993; p1-10.

19. Hsu W, Wang AG. Nasopharyngeal carcinoma with orbital invasion. Eye 2004; 18: 833-8.

20. Neel HB III, Taylor WF. Clinical presentation and diagnosis of Naso-pharyngeal Carcinoma : Current status. In Prasad U, et al. (eds) : Nasopharyngeal Carcinoma Current concepts. Kuala Lumpur, University of Malaya Press. 1983; p10-20. 